\title{
Animal em movimento
}

\author{
Luiz Fernando Medeiros de Carvalho \\ Universidade Vale do Rio Verde
}

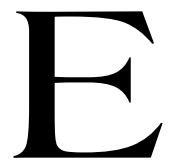

m Numeral/Nominal, último dos livros que integram a alentada edição de sua poesia reunida, o poeta Armando Freitas Filho formula a obsessão com o tempo como força do limite - como se o ponto extremo a que sua obra estava alcançando ameaçasse paralisar a mão que escreve através do exercício minucioso e exaustivo do testemunho da passagem do tempo que impregna todas as coisas.

No poema "Móvel", por exemplo, vemos a inusitada descrição plástica de uma natureza tornada morta:

Mesa seca, no osso, sem o viço de origem.

Com os quatro pés de esqueleto, já sem raízes

pisando na terra, prestes a se quebrarem.

A madeira é quase lenha que não lembra mais

Quando ousou folha flor fruto, vergou sua copa

e tronco, com os ramos estalando sob o vento.

Quando deu sombra e intervalo ao sol.

Quando foi árvore de onde a ave deriva.

Assim, dividido em duas metades nítidas, o poema contrasta ostensivamente o arquivo da árvore/natureza com seu estágio atual na dimensão da cultura. Para isso, o olhar retrocede no tempo de modo a flagrar os possíveis cenários de onde o objeto do presente teria vindo, numa leitura exemplarmente transgressora: para fora do temático, para fora do utensílio e para fora do humano. E com esse procedimento o poema apresenta aquilo que considero a armadura geral de todo o livro e também seu particular ensinamento, constituído pelo registro obstinado de um modo de olhar que instaura um outro modo de usar o objeto sobre o qual se debruça - ambos, não por acaso, móveis.

Trata-se de um móvel, apenas. É como se o olhar testasse nas coisas o que vai percorrer nas pessoas. Da constatação, entretanto, surge um visgo contido naquela exuberante e antiga árvore. Esse traço de melancolia é a componente da aporia. A árvore é viva, lugar de vivacidade e o poema 
também se quer vida, vai para o papel não para morrer. Como suporte metonímico do poema, a mesa, entretanto, envia o aviso de que pode se quebrar. A mesma mesa que produz a vivacidade do vivo no poema é pensada como lugar de impasse.

O deslocamento do olhar concentra-se no humano. A corrosão no tempo, agora não mais na perspectiva da origem, mas na do deslocamento para o futuro. Entre a origem e o futuro.

Em "10 anos", é o numeral que aparece seguido pela dedicatória ao filho Carlos. O que é dito é ainda força de futuro, irrupção. Tudo é preparação para o aguçamento do princípio corrosão: "Mas a infância já se feriu, inevitável/ ao entrar na casa dos dois dígitos para sempre".

Observe-se a utilização da expressão adverbial "para sempre" como acelerador do processo teleológico da corrosão, até chegar à palavra "prazo": "A dor de alterar-se, de altear-se/ estala, e a inocência também é de sangue./Uma e outra se quebram e reanimam-se:/têm o mesmo comportamento, prazo/ bravio e breve, das ondas no mar."

"Ao tempo", último poema do livro, faz a passagem do natural ao humano pela meditação sobre a sua impossibilidade ou seu limite.

A referência ao "teto alto da tarde" enuncia a corrosão provocada pelo tempo, a sua atuação permanente. Esse exercício que o poema realiza de escavar o tempo, de mostrar as marcas de sua passagem nos seres poderia levar a uma paralisia, a uma constatação de impasse, de impossibilidade de enxergar algo de transformador. Mas não há o cultivo da melancolia, no sentido de se olhar para a série temporal e se fixar em alguma lembrança idealizada do passado.

O poema "Império" reúne as referências sobre a data 11 de setembro e encena o antes e o depois do acontecimento. Agora toda a concentração corrosiva funciona para pensar o acontecimento político. Forma plástica de dizer o poema através da experiência concretista visual, dizer com outros signos para além do verbal.

Poema da meditação sobre o estilhaçamento da unidade. Nomeia o número, identifica o número e trabalha a ruptura de sua unidade. No poema "Império" concentra-se toda a poética do livro: fazer surgir de um todo as microformas da dispersão e do corte, ao mesmo tempo ponto máximo da encenação da corrosão e resposta múltipla à paralisia. Ali onde existe a ponta de resistência do uno, a divisibilidade age.

Eis a cena da dispersão da unidade, a cena em que o poema apresenta o seu modo de desfazer o disfarce da unidade para pensar poeticamente o múltiplo: 
Torres. Terror. Cada uma parece

Um 1. As duas juntas marcam

o dia do espetáculo e a soma

dos alvos prateados em fundo

azul matinal 1 minuto antes.

1 minuto depois o que foi 1

Número íntegro se parte em N

Não se trata de um poema sobre um acontecimento. O exercício é sobre a linguagem na sua poderosa proliferação transgressiva, para fora da organização de um centramento do olhar.

O ponto central do poema é a realização visual das duas concentrações de unidade assinaladas pelo numeral no início e no fim do poema: "1 minuto depois o que foi 1", realização formal da idéia de unidade, da idéia de centramento da soberania, e sua transformação visual em N, semioticamente realizando a queda, a transição para o nada, para o zero.

1 minuto depois o que foi 1

número íntegro se parte em $\mathrm{N}$

em 1001 decimais do que era

uno de sol, vidro, aço, pedra e

esplendor no dia 10 e agora é 0

Essa proposta de explosão da unidade em favor da promessa de multiplicidade articula-se com a receita de poema que abre o novo livro Raro mar. O que estava escondido por uma operação de atenção nos processos corrosivos provocados pelo tempo e que deixou em reserva ou excluiu possibilidades, agora é o que vai ser aproveitado pelo novo poema e pelo livro todo.

O que vem pela fronteira da leitura ao se abrir a primeira página do livro é a experiência com a hospitalidade ao fragmento, ao desdobramento de perspectivas.

O novo livro abre com uma receita que desarquiva e aciona o múltiplo. Traz para dentro do livro o poema de João Cabral "Catar feijão" para ver o que escapou daquela primeira poética, o que não foi proposto pelo grande interlocutor.

No pórtico do livro, como um ritual de iniciação e de nova formulação, o poema "Outra receita" vai fazendo da sobra e do resto o processo de composição do livro que se anuncia. 
A interação com a poética de Cabral não acontece na clave de uma continuidade com o legado daquilo que os formalistas chamaram de estranhamento. Ao contrário de uma experiência radical com a desautomatização, a nova receita proposta na abertura do livro Raro mar é o acolhimento de qualquer significante na mesa, lugar de escrita e de substituição da pedra quebra dente cabralina pela inquietação do que está no ar, iminente, lugar "onde se admite tudo - o eco, o feno, a palha, o leve".

Escrever, para Armando, neste livro, passa a ser lidar com o paradoxo de dizer o que está sempre por vir, que se traduz na sua poesia como animal em fuga. A mesa que produz a escrita nunca se acalma porque o animalverso está sempre em fuga. A mesa não é um lugar fechado, mas poroso.

O problema lançado neste livro é como manter vivo o animal uma vez capturado, caçado pela página. O grande tormento do sujeito lírico é como não transformar o vivente imaginado com ar e músculo num ser paralisado pela escrita. O poema de número 42 afirma que o verso é um animal arisco que escapa à mão caçadora. Mas escrever é circunscrever. Circunscrever paralisa o movimento, cria o inerte. E criar o inerte seria retornar ao estágio do olhar pousado sobre as coisas, encenado no livro anterior, e que configura uma ausência de tensão ao aproximar-se do inorgânico. No livro anterior a mesa não era referida como o móvel da escrita. Em "Duas mesas", o móvel retorna na condição de mesa para o poema, entendido como tensa atividade ascética que nunca se livra da condição de deserto e ameaça. A ameaça de que falava o poema "Outra receita" ressoa neste outro como o temor de que o trabalho da mão resulte em fossilização pela inscrição na página daquilo que é puro movimento, transformando a escrita literária em pedra tumular.

O livro Raro mar alimenta-se dessa tensão entre o que se escreveu, o que se leu e o que ainda está oculto. O grande desafio do livro está em alimentar com a mão o animal arisco e movente, que não quer ser preso, como o poeta inevitavelmente opera ao escrever sobre ele. Por isso o verso precisa na escrita - apesar dela e devido a ela - ser pensado como livre. Livre da mão caçadora.

\section{O suporte como engendramento do poema}

Procuramos caracterizar como a poesia de Armando Freitas Filho tem elaborado um modo de olhar a transformação operada pelo tempo nas coisas para mostrar o efeito de sua passagem no humano. Procuramos 
explorar outros ângulos de leitura do livro Raro mar, último publicado em 2006 pela editora Companhia das Letras e que continua a instigar múltiplas interpretações. É sobre ele ainda que este texto se debruça, articulando-o com o mais recente lançamento do poeta que é um livro proposto como objeto de arte, produzido através de manufatura serigráfica. Armando inaugura uma nova série singular: um livro evento que coloca em discussão o ato de escrever, o ato de publicação e a discussão dos materiais que configuram e dão consistência ao ato de escrever. Trata-se do livro intitulado Para este papel, com tiragem de cinqüenta exemplares, numerados de 1 a 50, lançado no Pop, no dia 20 de outubro de 2007.

Escrevíamos no início que em Raro mar o verso se posicionava como verso livre em relação à mão caçadora. Agora acrescentamos que toda a meditação do poema sobre uma mesa enquanto apenas móvel, objeto utensílio no seu estatuto de ex-árvore, redimensiona-se investida da função de suporte da escrita.

A árvore aparada de pássaros do poema "Móvel"- poema seminal inscrito no livro anterior Numeral/Nominal, que dispara confrontos articulatórios com outras transformações de mesa - reaparece em Raro mar no poema "Duas mesas". A antiga árvore dimensiona-se, tornada horizontal para o deserto da escrita, sem paisagem, mas também sem nostalgia, sem melancolia, no fluxo proposto pela nova receita, conforme a poética do primeiro poema do livro Raro mar.

Armando inscreve seu poema e seu livro na lógica contemporânea dos fluxos de leveza sem abolir o pesadelo, a ameaça. O que interessa agora é observar a árvore na sua condição de móvel-mesa, enquanto suporte para a escrita. O que se discute é essa relação de pregnância entre o que se configura aparentemente exterior, de fora, à margem, e que no entanto contamina inteiramente. O suporte aparece como engendramento do poema. Fluxo que recebe o influxo da mão que escreve e que instabiliza a aparente passividade da mesa.

Inquieta, subjetivada, a mesa é nomeada também como o aramado que prende o animal músculo que, livre, no entanto se aprisiona na escrita. A poesia se alimenta desse ser vivente que alimenta e é alimentado pelo aramado que se arma na mesa. A fibra vegetal se transforma em metal produzindo permutações da materialidade.

Não só o suporte se transforma como a vertente animal da poesia de Armando se metamorfoseia em múltiplas componentes. Há nesse sentido 
um ponto de vista, um olhar, uma perspectiva de observação. Um olhar à espreita, um olhar interessado na captura mais que na contemplação.

Não é da ordem da contemplação o gesto do animal. Ele fica à espreita.

Mas o que é ficar à espreita? Uma ação se movendo na direção do tempo-espaço de observação poderia ser uma boa resposta para a pergunta sobre a espreita. Ação de escrever, ação de ficar à espreita.

Estamos falando de uma centralidade na poesia de Armando que vem se depurando há muito no sentido da oferta abissal de múltiplas dobras de observação, que irrompem em picos de cenas de explicitude sexual, para depois subsumir em corrente subterrânea de outros temas e textos retornando sempre insidiosos, siderando o campo de atração para um olhar cada vez mais depurado. Em Raro mar o poema que concentra a força de todas as imagens do livro e de imagens de paraíso, felicidade ou gozo, intitula-se Segredo, que retira discretamente de cena o seu sujeito lírico observador. O que aparece é a descrição implicada evidentemente desse sujeito interessado em se colocar ali naquele lugar, aparentemente estático. Aparentemente passivo, gera toda a atividade como quis bem nomear Courbet no seu A origem do mundo, que também é um quadro aparentementee descritivo. Trate-se do sexo feminino descrito plasticamente: o verbo exasperar contém o aspecto verbal de movimento de superação de uma passividade, uma promessa de ação inclusa na descrição que prepara o outro poema articulado com este e que mostra o trabalho das mãos no sexo e na feitura dos poemas. A descrição se configura como uma preliminar para a relação que se instaura no poema "Enfia a mão até achar no túnel" (poema 63):

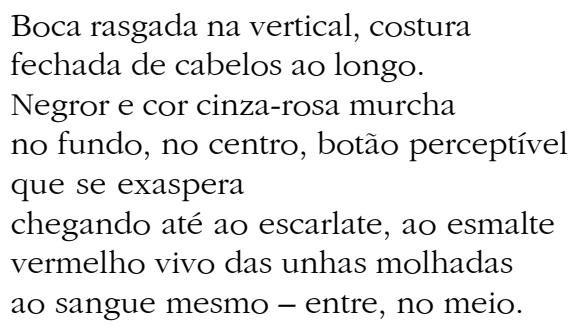

O poema 63 é construído pela ambigüidade de uma voz que comanda um tipo de receita, um performativo de comando: "Enfia a mão até achar no túnel" (observe-se a posição da mão, a mão que traça e que agora traz e atinge e toca). O poema se divide em duas partes como que 
espelhadas. A primeira comandada por este performativo que faz surgir o contato com o segredo, com algo que está retirado da visão e que só pelo toque se conhece: "Enfia a mão até achar no túnel/ o miolo ainda úmido, sem pavimentação, molhado por um resto de mar, sentindo com o dedo o segredo/ o ritmo íntimo da trilha, do trilho/ se forjando em riste no calor". O segredo é da esfera da intimidade, do interior que se dá a conhecer pela repetição quaternária de ritmo, intimo, trilha e trilho. $\mathrm{Na}$ segunda parte espelhada, outra vOz narra o que se observara na primeira estrofe, como que a narrar o efeito da travessia pelo corpo de alguém, tornado personagem: "Entra então estranho/ no subterrâneo da indecisa identidade/ e apesar de toda prospecção/ não descobre nunca a linha salvadora/ que justifique este esforço repetido/ de encontrar a saída para o firmamento".

Suscitar a cena sexual, ao mesmo tempo que convocar suas múltiplas nuances, como a que aparece agora neste novo livro Para este papel, no poema dedicado a Cri, que fala do sexual, mas da leveza de inscrições na pele do poema e da mulher.

$$
\begin{aligned}
& \text { Sua pele, sua palma aberta } \\
& \text { aceita minha escrita leve. } \\
& \text { Se a força de antes, que calcavas } \\
& \text { e foi, o que ficou, perto do fim } \\
& \text { ainda deseja cobrir, com amor } \\
& \text { a distância inconquistável, talvez } \\
& \text { talvez por natureza, terra de ninguém }
\end{aligned}
$$

Neste poema de Para este papel o poeta faz convergir a ação de escrever com a ação de amar. Trata-se de calcar o corpo com delicadeza sem perder a força - e é tudo o que o amor pede. O poema inscreve o risco da perda, o risco da não força, para se superar, no performativo do dizer: escrever é cobrir, amar é cobrir, descobrir é fazer. O livro dos véus que se descobrem chega ao ápice de dizer o trabalho das mãos no poema e no amor que se faz incessante.

\section{$O$ ato de escrever}

O homem é um animal que escreve. E resiste à sublimação. A mão é o seu médium e resistência ao controle escópico. Se o olho olhasse para a mão ela se destruiria. O olho olha para outra coisa e a mão pode se 
movimentar à deriva no movimento inconseqüente sem teleologia. A mão fala outra língua: inconsistente, insistente, inexistente para os olhos. O olho não percebe o que a mão faz.

"O verso livre tenta passar [...]". A travessia do verso é essa operação oxímora, contrastiva, em que se inscreve novamente a questão da liberdade, a liberdade do verso em relação às amarras da forma, tal como ensinou o modernismo. O verso no aprendizado do modernismo é livre. Na releitura desse aprendizado em Raro mar produz-se uma tensão inédita com o paradoxo dos extremos, uma luta entre o que já se escreveu, o que se leu e o que não se decifrou ainda. Um confronto entre a musculatura que pode se enrijecer, gerando artrite e não captando o que está no ar, e o que está no ar ainda e pode vir a florescer por entre mãos que captam através de um músculo flexível. Mão cega que produz pelo toque, aberta aos sentidos. A primeira vibração que sintoniza com o ar: "O verso livre tenta passar". Essa é uma sentença produzida pelo poema para logo em seguida ser obstruída pela deriva do desejo, por pseudoarmadilhas onde se diz tudo, onde se diz que tudo vem pela borda, pelo viés, pelo entorno ou como para confirmar a citação de que "contorno é ponte", o poeta sabe que se aproximar é sempre pela borda, lá onde "os gerânios deflagram". O poema acontece como um ápice, como gozo da escrita, mesmo assumindo a força do verso, como fez Oswald de Andrade, sem medo de assinalar, sem medo da chave de ouro. Na limpidez de uma frase simples ("O verso livre tenta passar"), seguem-se píncaros de contornos para encenar o êxtase, e é de êxtase que se trata a arte de movimentar a mão com a qual se desenha a intensidade da encenação do ato de escrever:

O verso livre, feito de ar e músculo tenta passar, na folga dos motores, o que foi escrito, com o que se leu e com o que é ilegível, que ainda está lá, no lado oculto da lua se desenhando à medida que se capta a primeira vibração, dentro da mão cega entre as paredes verde-água do Rio na boca, na borda do vaso onde os gerânios deflagram 


\section{Para este papel}

O livro recém lançado Para este papel traz mais uma vez a experiência com artes visuais e gráficas que sempre acompanharam a trajetória do poeta. Dessa vez a experiência se intensificou e atingiu o nível mais radical e proximidade forte com as questões que desenvolve sobre o tempo. Trata-se mais uma vez dos efeitos materiais da passagem do tempo, do jogo entre transparência, permanência, fugacidade, desaparecimento total ou parcial, vestígios, desaparecimento do traço. Materialidade da escrita.

A mão de novo é convocada para agir com estas superfícies. Página a página a mão vai retirar o véu, anterior e transparente, para possibilitar que se toque com os olhos a outra materialidade. É preciso firmar a vista, ir e vir pelo labirinto de letras desenhadas à mão. Quando o sentido se forma pelo passeio dos olhos, de novo a mão destampa o escondido ou anunciado como nuvem desejante que a mão procura na sua fome expansionista de descoberta. Uma das descobertas é que a mão passa e o tempo passante é oferta das mãos. Como inscrever sem registrar o impasse de ficar retido, de enclausurar o arisco movimento que necessariamente escapa. Como o bloco mágico na leitura de Derrida. Como o bloco mágico que se desprende do desenho e se mostra como velado enquanto a mão revela a inquietude de saber que o movimento não tem retorno.

A mágica é fazer acontecer esse cinema dos instantes.

Destapar infinitamente o mundo da escrita. Modo de rosto que não se quer imagem, mas sempre alteração. Ou como afirma Jorge Coli a respeito das cópias de Veronese: "A dimensão mais crucial da arte está na aparência, não na matéria. A característica mais fundamental da arte é imaterial [...] Perder sua materialidade de coisa é o que lhe permite passar do original para as cópias, réplicas, citações, lembranças, múltiplos”.

Em Armando não há o fetiche da arte como relíquia. Há a brincadeira do fort/da. Brinca-se de constatar o perdido, mas na clave de uma reinvenção dos materiais. Trata-se de uma imaterialidade que resultou como inanidade na ânsia que a mão tem em executar a inscrição do fugidio. Assim se pode ler de que matéria se constitui esse livroevento que aproxima a materialidade do suporte com a força da inquietante estranheza do animal. Para além do risco da sedimentação do inorgânico, superando-se na vitalidade da instalação-livro. 


\section{Referências}

CARVALHO, Luiz Fernando Medeiros de. O verso livre e a mão caçadora. Diário Catarinense, Florianópolis, 22 set. 2007, nํㅡㄴ 241.

COLI, Jorge. Ponto de fuga. Folha de São Paulo, São Paulo, 21 out. 2007, Suplemento Mais.

FREITAS FILHO, Armando. Numeral/Nominal. In: Máquina de escrever: poesia reunida e revista. Rio de Janeiro: Nova Fronteira, 2003.

FREITAS FILHO, Armando. Raro mar. São Paulo: Companhia das Letras, 2006.

FREITAS FILHO, Armando. Para este papel. Rio de Janeiro: Zen Serigrafia, 2007.

\section{Resumo}

Este ensaio investiga como a poesia de Armando Freitas Filho tem elaborado um modo de olhar a transformação operada pelo tempo nas coisas para mostrar o efeito de sua passagem no humano. Essa mirada não abrangeria apenas acontecimentos vividos na perspectiva de sua ocorrência no passado, mas desdobraria insights sobre a inquietude da cena contemporânea. Nos três últimos livros, intensifica-se uma dramaturgia da escrita onde se destaca o jogo entre o ato de escrever e os suportes materiais da escrita. Desse embate surge uma imagem do verso proposto como animalidade mutante, configurada na multiplicidade daquilo que não se paralisa ao se converter em texto.

\section{Résumé}

Ce texte montre de quelle façon le poète brésilien Armando Freitas Filho déploie un regard sur le travail du temps parmi les choses et les effets sur 1'humain. Ce regard n'appartient pas aux événements vécus autrefois, mais glisse vers l'inquietante étrangété du présent. Dans ses dernières ouvrages, on voit augmenter une dramaturgie de l'écriture autour de l'acte même de production du trait littéraire et les conditions matérielles de acte d'invention du langage. Dans l'imminence de ce combat, la trace du poétique dévient le visage d'un animal en fuite, produit dans la dispersion d’un être qui est en train de devenir texte. 